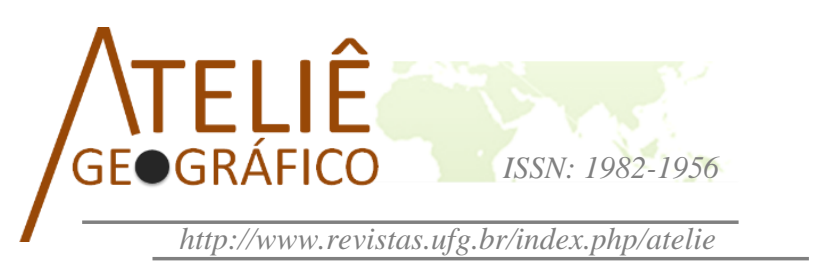

\title{
ComunicaCidade, ou como a cidade se comunica
}

\author{
ComunicaCity, or how the city communicates
}

ComunicaCiudad, o como la ciudad se comunica

\author{
Ivan Fortunato \\ Instituto Federal de São Paulo, Itapetininga \\ ivanfrt@yahoo.com.br
}

\begin{abstract}
Resumo
O objetivo deste artigo é apresentar a cidade - qualquer cidade - como um meio de comunicação, para que essa perspectiva possa ser incluída em estudos geográficos e/ou interdisciplinares. Escrito sob a forma de ensaio, o artigo foi pensado da seguinte maneira: existem evidências que demonstram que a cidade se comunica. Assim, as evidências encontradas foram sistematizadas uma a uma, cotejando a literatura base com as vivências de pesquisa desenvolvidas sobre um lugar específico da cidade de São Paulo. A primeira evidência diz respeito a "ver e ouvir" com atenção a cidade, a segunda, "o patrimônio e a ordem subjacente", trata de como o ambiente construído participa da comunicação e, a terceira, "o patrimônio e a subjetividade", diz respeito ao envolvimento pessoal com os lugares da cidade. Ao final, as evidências elencadas são relacionadas entre si, mas tudo o que se espera é contribuir com futuras pesquisas - quem sabe, sobre a égide de uma ComunicaCidade.
\end{abstract}

Palavras-chave: São Paulo; Centro Histórico; Geografia.

\begin{abstract}
The aim of this paper is to present the city - any city - as a means of communication, so that this perspective may be included in geographical and interdisciplinary studies. Written as an essay, this paper has been designed as follows: there is evidence that the city communicates. Thus, the evidences found were systematized individually, by comparing the literature with research experiences developed on a specific place in São Paulo. The first evidence concerns "seeing and hearing" with attention to the city, the second, "patrimony and the underlying order", deals with how the built environment participates in communication and, thirdly, "patrimony and subjectivity", ir concerns the personal involvement with the places of the city. In the end, the evidences listed are related to each other, and it is expected to contribute to future research - perhaps under the aegis of a ComunicaCidade.
\end{abstract}

Keywords: São Paulo; Historic Center; geography. 


\begin{abstract}
Resumen
El objetivo de este trabajo es presentar la ciudad - cualquier ciudad - como medio de comunicación, por lo que esta perspectiva se puede incluir en estudios de la geografía y interdisciplinarios. Escrito como un ensayo, este artículo fue diseñado de la siguiente manera: hay evidencias que demuestran que la ciudad se comunica. Por lo tanto, las evidencias encontradas se sistematizaron uno por uno, comparando la literatura base con experiencias de investigación desarrolladas en un lugar específico en Sao Paulo. La primera evidencia se refiere a "ver y oír" con atención la ciudad, la segunda, "el patrimonio y el orden subyacente", trata de cómo el ambiente construido participa de la comunicación y, la tercera, "el patrimonio y la subjetividad", se refiere a la participación personal con los lugares de la ciudad. Al final, las pruebas enumeradas están relacionadas entre sí, pero todo lo que se espera que contribuya a la investigación futura - tal vez bajo los auspicios de un ComunicaCidade.
\end{abstract}

Palabras-clave: São Paulo; Centro Histórico; geografía.

\title{
Ensaiando um conceito
}

\begin{abstract}
Marcovaldo tinha um olho pouco adequado para a vida da cidade: avisos, semáforos, vitrines, letreiros luminosos, cartazes, por mais estudados que fossem para atrair a atenção, jamais detinham seu olhar, que parecia perder-se nas areias do deserto. Já uma folha amarelada num ramo, uma pena que se deixasse prender numa tela, não lhe escapavam nunca: não havia mosca no dorso de um cavalo, buraco de cupim numa mesa, casca de figo se desfazendo na calçada que Marcovaldo não observasse e comentasse, descobrindo as mudanças da estação (CALVINO, 1994, p. 7).
\end{abstract}

Com ajuda da epígrafe, exponho o objetivo deste ensaio: apresentar a cidade como um meio de comunicação. Tal comunicação pode ser expressa, como os avisos, letreiros e demais produtos "estudados para atrair atenção", seja para evitar algo, se comportar de determinada maneira, comprar algum produto ou consumir algum alimento. Mas, essa comunicação também pode se dar de forma anuviada, ocultada pela obviedade do que é fabricado para direcionar a atenção, ou pela própria subjetividade que não consegue (ou não quer) encontrar representações de si na casca de figo se desfazendo, ou na quase insignificante mosca no dorso do cavalo, ou pela própria organização do espaço urbano, construído, mesmo que ao acaso, como forma de comunicar à sua própria população sobre os locais de encontro, de compras, de passeio etc. bem como a quem se deve obedecer - este, geralmente, a construção maior ou mais alta, que se torna ponto de referência.

Com isso, pode-se introduzir a noção de ComunicaCidade: um jogo de palavras que combina a Comunicação (pensada como transmissão de mensagens), e a Cidade (como o espaço urbano habitado), para imprimir a ideia de que a Cidade pode ser entendida como um Meio de Comunicação. Não se trata de delinear uma teoria pronta e acabada, que deve integrar os anais das ciências, mas, antes, de apresentar algumas 
evidências que permitam incorporar essa perspectiva nos estudos interdisciplinares, cada vez mais emergentes na própria geografia.

Assim, o que se espera lograr com este ensaio é a ampliação dos sentidos do patrimônio construído, possibilitando que sejam compreendidos e investigados, à luz da ciência, como elementos que recuperam a memória e repercutem o momento cultural. No cotidiano de uma cidade, isso implica assegurar que as ruas se configuram como o suporte midiático dessa comunicação que perpassa as três dimensões espaciais e o continuum temporal. E, se triunfar ao apresentar o desenlace deste ensaio, posso até ambicionar que o vocábulo utilizado no título se torne um conceito que figure entre os tantos que impulsionam a ciência. Assim, até consigo imaginar futuros pesquisadores refletindo como a ComunicaCidade interfere ou é modificada pelo desenvolvimento tecnológico, pela expansão urbana, pela organização do espaço e pelas transformações culturais.

Para balizar essa pretensiosa ideação, tomo como exemplo do cotidiano vivido, elementos que vieram à tona quando estava em campo, tomando notas para tese de doutorado em geografia sobre o sítio urbano mais antigo da cidade de São Paulo, o Pateo do Collegio (FORTUNATO, 2014). Esse lugar está no Centro Histórico de São Paulo, em uma área conhecida como Triângulo Histórico. Foi aí que os padres jesuítas, depois de uma fraterna relação estabelecida com a tribo local, encontraram lugar ótimo para instalar igreja e colégio.

Ao recuperar a história de ocupação desse lugar pelos jesuítas, na década de 1550, foi possível identificar três motivadores basilares para a seleção desse local: (1.) estava no sertão de uma capitania sediada no litoral, sendo que o plano de tomada do território demandava que mais áreas fossem colonizadas; (2.) sua geografia era perfeita, pois era um descampado no meio da mata nativa e estava entre dois rios, onde a terra era fértil, havia peixes e água; e (3.) ficava no alto de uma colina, permitindo ver e ser visto de longe (FORTUNATO, 2015).

Este terceiro motivador se torna importante elemento que dá força à ideia de que a cidade se comunica, afinal, os jesuítas estavam replicando o que se fazia na Europa: as igrejas deveriam ser edificadas no alto, ou suas torres deveriam ser muito altas para que, de longe, os habitantes e/ou os forasteiros não tivessem qualquer dúvida sobre a presença da fé cristã no local. Ainda, é possível considerar a altura como símbolo de poder, conforme Hillmann (1993), para quem o gigantismo da humanidade, que se repete nas suas construções, seria a representação dos deuses na Terra.

Para alcançar os objetivos apresentados, este ensaio foi pensado da seguinte maneira: as evidências encontradas foram sistematizadas uma a uma, cotejando a literatura base com a área do Pateo do Collegio. Ao final, as evidências elencadas são relacionadas entre si, mas tudo o que se espera é contribuir com futuras pesquisas quem sabe sobre a égide de uma ComunicaCidade. 


\section{Evidência um: ver e ouvir}

A perplexidade é compreensível, pois a leitura da cidade não é fácil nem estamos armados de instrumentos teóricos adequados para tal análise. Compreende-se, por isso, que ante a realidade complexa muito urbanista prefira fechar a janela e passar a ler textos, quadros e informações indiretas a respeito dessa cidade que está lá fora. Face à ausência de um instrumental seguro, em lugar de tentar inventar, de experimentar métodos para enxergar a cidade, prefere limitar-se a um exame quantitativo, útil porém insuficiente (WILHEIM, 1976, p. 58).

O arquiteto Jorge Wilheim (1976) foi um dos mais importantes reorganizadores do espaço urbano da capital paulistana desde os anos 1960, incluindo o projeto de revitalização da área do Pateo do Collegio, na década seguinte. Essa relação entre o urbanista e o lugar que dá força às ideias de ComunicaCidade, ultrapassa a mera coincidência. Isso porque, quando essa metrópole se comunica com seus pesquisadores, as peculiaridades de seu local de nascimento não são ocultadas.

Mas, para além desse lugar em comum, um dos legados de Wilheim (1976) é uma metodologia para leitura das cidades. No trecho da epígrafe, o arquiteto registrou a ausência de "instrumentos teóricos adequados" para uma leitura das cidades, que dessem conta de sua complexidade. Quatro décadas se passaram, e os instrumentos continuam a ser calibrados, desenvolvidos, criados, mas, é coerente afirmar que ainda não se delineou uma perspectiva teórica capaz de dar conta dessa interpretação.

Disso deriva sua crítica às ações de gabinete: deve-se abandonar a segurança dos dados quantitativos, das paredes dos escritórios e das pranchetas inanimadas, pois a transformação somente poderia acontecer por meio da criatividade de métodos experimentais, na "cidade lá fora", que teriam calibre suficiente para "enxergar" a cidade. Com isso, o autor indicou a presença in vivo nos lugares da cidade, nas suas ruas e entorno, como metodologia para que a comunicação seja decodificada e compreendida. Do lado de fora dos escritórios, portanto, pode-se iniciar um processo consciente e voluntário de comunicação com a cidade: "Costuma-se dizer que a paisagem urbana comunica informações a seu respeito, sendo, portanto, possível a sua leitura. Esta implica percepção. Qual o cientista, o urbanista deve poder observar para perceber o que há atrás e dentro da paisagem urbana” (p. 59).

Essa relação entre estar, observar e perceber, encontra respaldo nas palavras do psicanalista James Hillman (1993). Embora sua preocupação fosse a saúde mental das pessoas citadinas ${ }^{1}$, suas reflexões mais do que resvalam nas propostas do arquiteto, especialmente quando apresenta o seguinte: "vistas das pranchetas dos arquitetos e das plantas dos urbanistas raramente mostram uma multidão. Em vez disso, casais passeiam sob as árvores, pessoas surgem uma de cada vez saídas dos carros estacionados” (p. 52). Este trecho ratifica a ideia de que a complexa comunicação urbana parece incomodar

\footnotetext{
${ }^{1}$ Aproximadamente $55 \%$ da população mundial vive nas cidades (UN, 2015).
} 
quem pensa sobre uma cidade, sendo mais seguro e confortável imaginar que uma rua não é o que ela é. Ainda, para Hillmann (1993, p. 56): “As cidades são ruas, avenidas de troca e comércio, o aglomerado físico de pessoas, uma multidão caminhando nas calçadas movidas por curiosidade, surpresa, pela possibilidade do encontro, a vida humana não acima da confusão, mas no meio dela".

Decorre, dessas constatações, que para (se) entender (com) uma cidade é preciso nela estar, do lado de fora, e sobre suas ruas caminhar. Somente assim é possível compreender e se surpreender com sua dinâmica vida cotidiana, e com as informações disponibilizadas pelas suas construções, sejam essas tangíveis ou intangíveis, atuais ou registros de memória.

Foi pensando de forma similar que Canevacci (1997) descobriu a importância de "perder-se" na cidade de São Paulo, logo nas suas primeiras visitas, de modo a tentar decifrá-la. Acostumado com sua cidade italiana, o gigantismo, o multiculturalismo e enigmático traçado paulistano pareciam falar-lhe em múltiplas linguagens simultaneamente, ocasionando ruídos desmensurados que prejudicavam sua comunicação. Foi assim que ele se permitiu caminhar por suas ruas, possibilitando guiar seu foco, o quanto fosse possível, a cada uma das linguagens em seu tempo. Daí, a seguinte afirmação é praticamente axiomática: "compreender uma cidade significa colher fragmentos" (p. 37). Um a um, esses fragmentos vividos ganham sentido, se fortalecendo quando se constrói entre eles "estranhas pontes, por intermédio das quais seja possível encontrar uma pluralidade de significados. Ou de encruzilhadas herméticas" (p. 37).

Com isso, o autor se convenceu que compreender a cidade onde se está, requer escutá-la, mas também com ela falar; precisa que se observe suas ruas, sua arquitetura, sua gente etc., permitindo-se ser observado. Isso demanda, portanto, participar da cidade e deixar-se nela participar. Essa relação reflexiva, por sua vez, significa envolver-se plenamente com a cidade que se comunica, afinal, constatou Canevacci (1997, p. 37): "não somente vivemos 'nela', mas também somos vividos 'pela' cidade. A cidade está em nós".

Ao recuperar lembranças sobre minha própria chegada a São Paulo, percebo que fiz o mesmo que o antropólogo e me "lancei" na cidade, como que desejando nela me perder para me encontrar. Foi justamente ao flanar pelo seu Centro Histórico que encontrei com e me encantei pelo Pateo do Collegio. Em outro ensaio (FORTUNATO, 2017), descrevi essa particular experiência, nomeando o momento primeiro de topar com o lugar como "súbito encanto". Já afirmei que o Pateo nunca foi meu "objeto" de estudo, mas o lugar que mais me acolheu na metrópole. Essa área não é local sobre o qual tenho desenvolvido estudos por causa de seu legado histórico como sítio urbano mais antigo da cidade, mas por ter se tornado o núcleo onde, ao me lançar nas ruas de São Paulo com o objetivo de me perder, me encontrei.

Nesse entrelaçar da polifonia com a imagem e com a identidade, emergem linguagens que são capturadas por sentidos distintos, mas decodificadas pela percepção 
de alguém que compreende que compreender a cidade, não pode se limitar a observar a que está lá fora. Ferrara (2000, p. 85), que tanto discutiu a percepção como o canal mais apropriado para interpretar os signos da urbe, anotou que "um leitor da cidade é, obrigatoriamente, alguém sensível à sua imagem enquanto manifestação de cultura e suas variações". Essa sensibilidade, a da própria autora, inclusive, a levou a considerar a cidade como mídia. Assim, para elevar a visibilidade desta primeira evidência a respeito da ComunicaCidade, importante trecho se faz necessário reproduzir:

Apreender essa mídia, considerando seus suportes construtivos, nos leva a constatar que, às características urbanísticas e funcionais de uma cidade, alia-se a dimensão comunicativa que faz com que a cidade surja sempre e, sobretudo nos dias atuais, de um lado, como eficiente mídia a sustentar as ambições e planos globais e, de outro, nos surpreenda pelas imponderáveis e inesperadas manifestações de vida que vão muito além da simples intenção midiática (FERRARA, 2008, p. 41).

Essa ideia de que a cidade é uma mídia capaz de simbolizar o plano da globalização e representar suas manifestações vivas, dinâmicas, inesperadas, arremata toda argumentação sobre a primeira evidência. Nesse sentido, a essência para que a comunicação com a cidade aconteça se assenta sobre os seguintes elementos: (1) deve-se estar presente no lugar, (2) há que se considerar que a vida da cidade é a vida que se manifesta na cidade, (3) a comunicação se dá por múltiplas linguagens e se perder, intencionalmente, na cidade é uma forma de decodificá-las, (4) comunicar-se não é uma atividade puramente racional, pois demanda percepção e sensibilidade, e (5) a cidade é uma mídia.

\section{Evidência dois: o patrimônio e a ordem subjacente}

Em cada cidade do império, os edifícios são diferentes e dispostos de maneiras diversas: mas, assim que o estrangeiro chega à cidade desconhecida e lança o olhar em meio às cúpulas de pagode e claraboias e celeiros, seguindo o traçado de canais hortos depósitos de lixo, logo distingue quais são os palácios dos príncipes, quais são os templos dos grandes sacerdotes, a taberna, a prisão, a zona (CALVINO, 2003, p. 17).

A segunda evidência foi localizada com ajuda de Calvino (2003) que, ao ficcionar como teriam sido os diálogos entre Marco Polo e o imperador Khan, narrou sobre as várias cidades que o navegador teria visitado nas suas viagens exploratórias até o oriente. Calvino (2003) cunhou um termo capaz de explicar uma forma bastante sutil de comunicação das cidades, que é a sua "ordem invisível". Esta disciplina sua economia, educação, sistema legal, enfim, é uma ordem que conduz a cultura, prescreve sua identidade e mantém o poder. Por isso, o romance foi batizado de Cidades Invisíveis, em referência aos locais visitados por Marco Polo. Com olhar perspicaz para as paisagens citadinas, foi-lhe possível compreender que cada cidade tende a funcionar 
como um jogo de xadrez: ao olhar para o tabuleiro há um caos aparente, governado por um "sistema coerente e harmônico", conhecido por quem movimenta as peças. Em essência, a "ordem invisível" diz respeito ao conjunto de regras que grande parte da população o conhece, e o respeita ao longo do "jogo".

A perspectiva mais evidente dessa ordem invisível é a altura dos elementos construídos: quanto mais alto for, maior a sua presença local. Ferrara (2008) também sustenta essa ideia da verticalização como mídia. Assim, esse tipo de comunicação não pode ser tratada de forma trivial, uma vez que ela informa, a todos, como uma cidade se organiza - ou em que esferas se pode esperar algum tipo de enfretamento, se for contradita.

De certa forma, a "ordem invisível” está expressa na epígrafe, na qual o autor deixa explícito esse tipo de comunicação das cidades. Ao utilizar-se da figura de um estrangeiro, o autor explica como o patrimônio construído é capaz de informar sua própria organização - "a cidade é redundante", afirmou, "repete-se para fixar alguma imagem na mente" (p. 11). Não são apenas as placas, os símbolos e os habitantes locais que têm a capacidade de transmitir informações a respeito da ordem de uma cidade, pois o estilo arquitetônico, a localização, o tamanho e a altura do patrimônio construído denotam onde está, quem e o quê. O autor evidencia isso ao afirmar: "Se um edifício não contém nenhuma insígnia ou figura, a sua forma e o lugar que ocupa na organização da cidade bastam para indicar a sua função: o palácio real, a prisão, a casa da moeda, a escola pitagórica, o bordel”' (p. 9).

Desse modo, se essas ideias soam muito abstratas porque as cidades invisíveis são intangíveis, São Paulo, por outro lado, é bastante concreta. Assim, quando essa cidade foi fundada, em 1554, seus colonizadores eram da Companhia de Jesus. Qual foi o local escolhido para a edificação da primeira construção da cidade, utilizada pelos padres para a catequese dos gentis, para as missas e para as lições de línguas, matemática e ciências aos curumins e pequenos portugueses que habitavam o sertão paulista? Um descampado no alto de uma colina.

Como já delineado em outro ensaio (FORTUNATO, 2015), a geografia do local foi um dos elementos fundamentais para a seleção do lugar onde os jesuítas se estabeleceriam no interior selvagem, sendo que os indígenas o havia nomeado como Piratininga - o peixe no seco - indicando um ritmo de cheia e seca do rio (Tamanduateí) que tornava o solo muito fértil, além de o próprio rio fornecer água potável, peixes para alimentação e ser um curso navegável. Não só isso, pois o local que os jesuítas tomaram como ótimo para colonização do sertão era um descampado plano, em meio à nativa mata atlântica, o que facilitaria a construção de uma vila.

Havia outros descampados planos, como em Santo André da Borda do Campo, onde vivia o primeiro habitante português do interior paulista, João Ramalho. No entanto, o planalto de Piratininga fica(va) no alto de uma colina, possibilitando observar a aproximação de inimigos, mas, principalmente, permitindo que a cruz, símbolo máximo da igreja, fosse avistada de longe, ratificando a sua presença no local. 
Como a preocupação aqui é a perspectiva comunicativa do patrimônio urbano, se elipsam os desdobramentos culturais do planalto de Piratininga, a partir do qual a urbanização foi se desenvolvendo de forma concêntrica, sendo lenta até o último quartil do século XIX (cf. FORTUNATO, 2015). Sobre essas décadas finais dos anos 1800, a literatura é quase consoante a respeito de uma transformação radical na cidade: o que era um burgo de 20 mil habitantes, com ruas de barro, sobrevivendo da agricultura, repentinamente passa a ser referida como Metrópole do Café. Trata-se de uma época em que construções rebuscadas, de tijolo, em neoclássico, tomaram as ruas de uma grande cidade, enriquecida por causa do capital do café investido. Outras inovações foram chegando junto com o dinheiro, como a eletricidade, o bonde e o estilo luxuoso de vida (boutiques, chá da tarde e música erudita etc.).

Assim como o estrangeiro de Calvino (2003) reconheceria a ordem invisível de uma cidade a partir de sua paisagem, quem chegava a São Paulo logo identificava que aquela não era uma pobre cidade agrícola. A cidade lhes contava isso. Como? Dentre outros, pela fachada ornamental e pelo tamanho do edifício erigido pela arquitetura de Ramos de Azevedo, para assumir o lugar da igreja dos jesuítas (figura 1); pelo novo nome dado ao lugar, Largo do Palácio; e pela nova função do edifício, que há algum tempo já não era mais colégio-igreja, mas sede da administração pública.

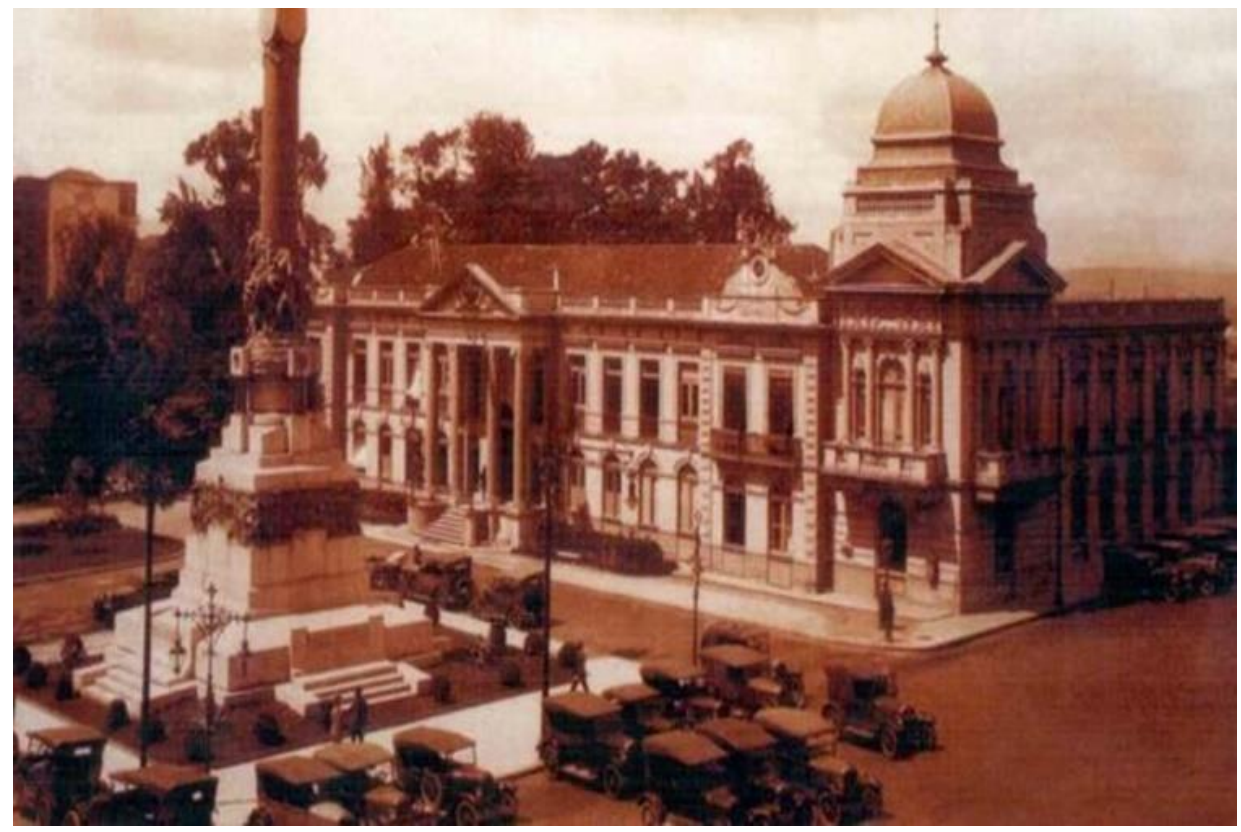

Figura 1: Palácio do Governo, no Largo do Palácio (1925). Arquivo pessoal; foto sem créditos.

Passadas a primeira guerra mundial e a crise financeira de 1929, a cidade paulista reconfigurou-se novamente. Dessa vez, as contingências foram desfavoráveis ao 
café, mas ideais para a industrialização: havia local para as fábricas ao longo das linhas de trem, sobravam trabalhadores excedentes da quase extinta mão de obra do café e do surto migratório, além de substancial mercado interno. A cidade já não poderia mais continuar emitindo informações de que ali prosperava o luxo. Foi dessa forma que as rebuscadas obras em neoclássico foram, metaforicamente, sendo diminuídas pela altura dos novos prédios, cuja arquitetura e material de fabricação já não eram mais europeus, mas vindos dos Estados Unidos, junto com o poder financeiro. No caso do local de nascimento da cidade de São Paulo, o Palácio do Governo não sobreviveu, tendo sido posto abaixo depois de longa e complexa mobilização da população, em defesa de sua memória. No seu lugar, foi construída uma réplica do conjunto colégio-igreja dos jesuítas da época de taipa (FORTUNATO, 2016b).

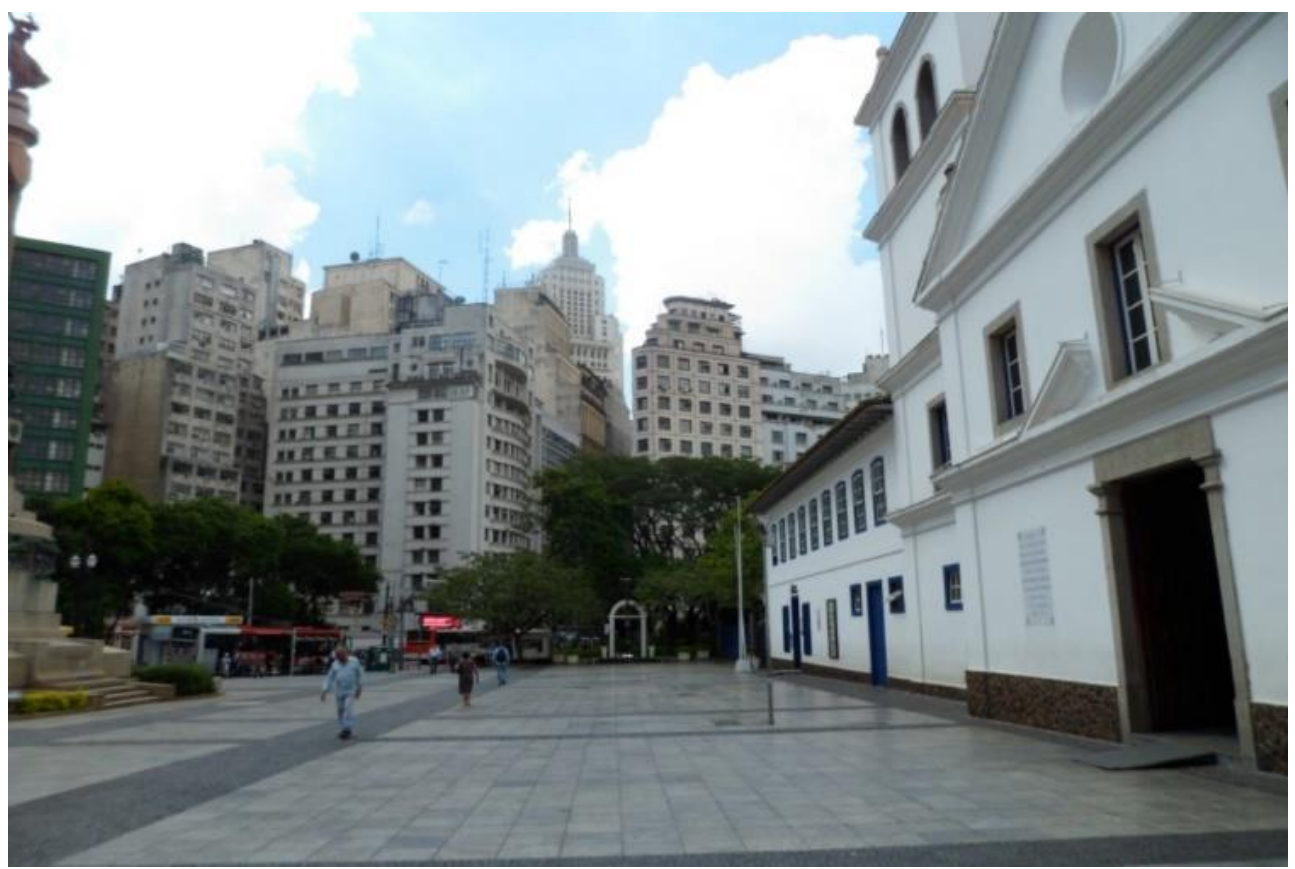

Figura 2: "Banespão", o mais alto e no centro, visto do Pateo. Foto: Ivan Fortunato, mar./2013.

Nesse ínterim, a verticalização passou a tomar conta da região central da cidade, seja para atender às crescentes demandas de moradia, escritórios e comércio (SOMEKH, 1997), seja para replicar, na paisagem, a superioridade das construções bancárias, conforme se delineava no país norte-americano. Surgia, assim, o Edifício Altino Arantes, o "Banespão", primeiro e mais notório edifício-símbolo, capaz de comunicar a todos que São Paulo havia deixado de vez a economia agrícola, tornando-se a cidade que representaria o capitalismo industrial no Brasil. Esse movimento de construir buscando alturas cada vez mais elevadas começou, e não ao acaso, no planalto de Piratininga, coincidindo com o local de nascimento de São Paulo. 
Assim, a cidade industrial fazia nascer, com capital dos bancos para os bancos, o Banespão - sede da instituição financeira que havia socorrido São Paulo, quando a cidade fazia dívidas por causa da falência do café. O edifício foi inaugurado em 1947, sendo o Pateo do Collegio testemunha de tão imponente ícone concreto do que a cidade tinha se tornado economicamente. A figura 2 revela, parcialmente, esse diálogo simbólico entre o sagrado e bucólico lugar de nascimento de São Paulo, e sua mais antiga rubrica que expressa a presença do capital industrial no logradouro primitivo.

Desde a última metade do século XX, essas distintas construções - de arquitetura colonial (imitando a taipa), de estilo neoclássico europeu (de tijolos), e de estrutura armada norte-americana - convivem no Triângulo Histórico, no alto da colina, no planalto de Piratininga. Essa convivência heterogênea do patrimônio não é apenas resto dos tempos pretéritos, pois comunica a cultura da cidade de hoje: um centro metropolitano altamente multiforme, que foi se formando com a imigração estrangeira desde o início da industrialização, ampliando-se cada vez mais, conforme a própria cidade crescia economicamente.

Assim, o que parece um caos é, possivelmente, uma "ordem invisível" extremamente ampla em tamanho e volume, e altamente complexa em suas relações. Por isso, tentar se comunicar com a capital paulistana, por meio de seu patrimônio, é uma tarefa praticamente impossível, por causa de sua magnitude. Por outro lado, é plausível dialogar com seus lugares, como o Pateo do Collegio, por exemplo, que tem muito a contar. Afinal, "a memória é redundante", escreveu Calvino (2003, p. 11), "repete os símbolos para que a cidade comece a existir".

\section{Evidência três: o patrimônio e a subjetividade}

Um edifício "se comunica" por meio de muitas linguagens, não somente com o observador mas principalmente com a própria cidade na sua complexidade: a tarefa do observador é tentar compreender os discursos "bloqueados" nas estruturas arquitetônicas, mas vividos pela mobilidade das percepções que envolvem numa interação inquieta os vários espectadores com diferentes papéis que desempenham. Espectadores que, por sua vez, ao observarem por meio de sua própria bagagem experimental e teórica, agem sobre as estruturas arquitetônicas aparentemente imóveis, animando-as e mudando-lhes os signos e o valor no tempo e também no espaço. Existe uma comunicação dialógica entre um determinado edifício e a sensibilidade de um cidadão que elabora percursos absolutamente subjetivos e imprevisíveis (CANEVACCI, 1997, p. 22).

Até aqui, foram apresentadas duas potenciais evidências a respeito da ComunicaCidade: a percepção do espaço construído e a decodificação da ordem subjacente. A terceira e última evidência elencada pode ser compreendida como a percepção de uma ordem subjacente. Para que essa evidência seja localizada na cidade, 
as idiossincrasias ampliadas pela percepção precisam ser cotejadas com as informações fornecidas pelo patrimônio observado. Assim, a imagem aparente pode deixar a superficialidade visual, para interatuar com a experiência, o conhecimento e os meios de análise de quem a observa, tornando-se uma imagem complexa porvir.

Além da imagem urbana e da subjetividade de quem a observa, há um terceiro elemento envolto nessa trama, que torna a decodificação da imagem mais labiríntica, difícil e significativa. Trata-se da existência ontológica dos lugares, minutada com mais propriedade em outro ensaio (FORTUNATO, 2016c). Ao permitir o envolvimento dessa dimensão na comunicação entre patrimônio construído e sujeito que o observa e quer compreendê-lo, a trama interpretativa pode seguir diversas trilhas, pois as linguagens mencionadas na epígrafe por Canevacci (1997) apresentam-se igualmente variadas. Isso, no entanto, não deve ser tomado como a relativização de tudo, nem a permissão para que qualquer linha de investigação seja tida como possível quando se está em evidência o estudo da comunicação na, da e para uma cidade.

Importante esclarecer que considerar a dimensão ontológica dos lugares, não é o mesmo que "humanizar" determinada área. Isso seria vulgarizar o sentido da existência de um lugar, além de infantilizar a ciência. Quando se apresenta o sentido ontológico, o objetivo é potencializar a comunicação que há nas cidades, pois um lugar não pode ser tido somente como um local modificado pelo bel prazer das pessoas. Pela geograficidade, Dardel (2011), nos anos 1950, já indicara que os lugares são muito mais do que "recipientes" da ação humana sobre a superfície terrestre, mas o repositório histórico da cultura, reciprocamente transformando-a ${ }^{2}$. A história do Pateo do Collegio como lugar na cidade de São Paulo, já delineada neste ensaio, é notório exemplo disso: o descampado no alto da colina não foi colonizado ao acaso, tampouco o desenvolvimento econômico, demográfico e urbano da metrópole aconteceu sem a participação direta do lugar.

Isso posto, o trecho de Canevacci (1997) reproduzido na epígrafe trata desse envolvimento tripartido na comunicação da cidade. No entanto, a concepção expressada pelo antropólogo precisa ser ampliada. Isso porque o autor se refere a um edifício, como se qualquer edifício tivesse qualquer importância - simbólica ou concreta - sem considerar o lugar que o abriga. Assim, não se trata apenas da reduzida relação edifíciocidade-espectadores, mas da complexa relação lugar-cidade-sujeitos (da mesma forma, estes não podem ser reduzidos a espectadores).

Uma vez tendo calibrado o proposto por Canevacci (1997), fica mais fácil concordar com suas ideias: há inúmeras linguagens para decodificar a comunicação da cidade, tais como a estética, a econômica, a histórica, a arquitetônica etc. Cada uma dessas linguagens não corresponde ao ideal da tradicional comunicação emissor-meiomensagem-receptor, pois todos os elementos do tripartido lugar-cidade-sujeito são

\footnotetext{
${ }^{2}$ Dardel (2011) tem ajudado muito a pensar a relação visceral que cria vínculos com lugares. Recentemente (FORTUNATO, 2018), afeto, paixão e orgulho por habitar nova cidade ajudou a pensar no conceito de geografiCIDADE, claramente parafraseando-o.
} 
agentes comunicacionais, portanto, o que é posto em comum entre eles emerge do diálogo, não da transmissão. Daí, a cidade vai se comunicando de múltiplas formas, em seus diversos lugares, com sua heterogênea população (habitantes, visitantes etc.).

Tudo isso, de alguma forma, ressoa com as palavras do antropólogo italiano que se deixou perder na metrópole paulistana, com o objetivo de tentar dialogar com essa cidade. Perder-se intencionalmente, talvez até mesmo antecipando e/ou se preparando para um provável ocaso - pois, com esse sim, vivenciaria uma conversa entre estranhos, em linguagens divergentes:

\footnotetext{
Na decodificação da mensagem existe sempre um lado criativo, um critério subjetivo. Ela é interpretada segundo a formação particular do pesquisador, sua biografia intelectual e política, seus gostos e emoções, ou segundo o acaso. A tradução da mensagem urbana é sempre uma traição (CANEVACCI, 1997, p. 37).
}

De certa maneira, o autor descreve e qualifica a comunicação entre o tripartido, deixando claro que, apesar da ontologia dos lugares da cidade e das múltiplas linguagens, somente o "pesquisador" decodifica e interpreta as informações por meio de "filtros" como a razão, a emoção e os gostos individuais, construídos e reelaborados ao longo de sua própria história de vida. Daí parece decorrer o predicado "traição", não como uma deslealdade a qualquer vértice do tripartido comunicacional, mas como uma ação tendenciosa que privilegia a si. Ainda assim, o advérbio "sempre" talvez seja uma traição em si, pois é possível serenar o olhar, e permitir que percepções distintas e/ou contrárias, incorporem a decodificação das mensagens, tornando-se uma interpretação coletiva - este é, ao mesmo tempo, o grande desafio e a importante contribuição do pesquisador para a ComunicaCidade.

Essa potencialidade de decodificar significados coletivos na comunicação com o Pateo do Collegio que permitiu reconhecê-lo como um lugar na cidade de São Paulo. Em retrospecto, posso até considerar que o princípio de nossa relação se deu conforme a descrição do antropólogo: uma traição ao lugar, em decorrência da minha particular percepção e das emoções que foram desencadeadas. Neste mesmo ensaio, ao tratar da evidência um, destaquei que o contato inicial com o Pateo do Collegio foi um "súbito encanto". Isso foi exclusivamente meu, que havia me perdido intencionalmente pelo Centro Histórico, com o propósito de me encontrar com a cidade. A imagem de nosso primeiro encontro, ocorrido há um decênio, está registrado na memória. Essa imagem está reproduzida na fotografia da figura 3, tirada quando já havia me tornado pesquisador do lugar. O que a foto não consegue reproduzir é a emoção do "encanto". 


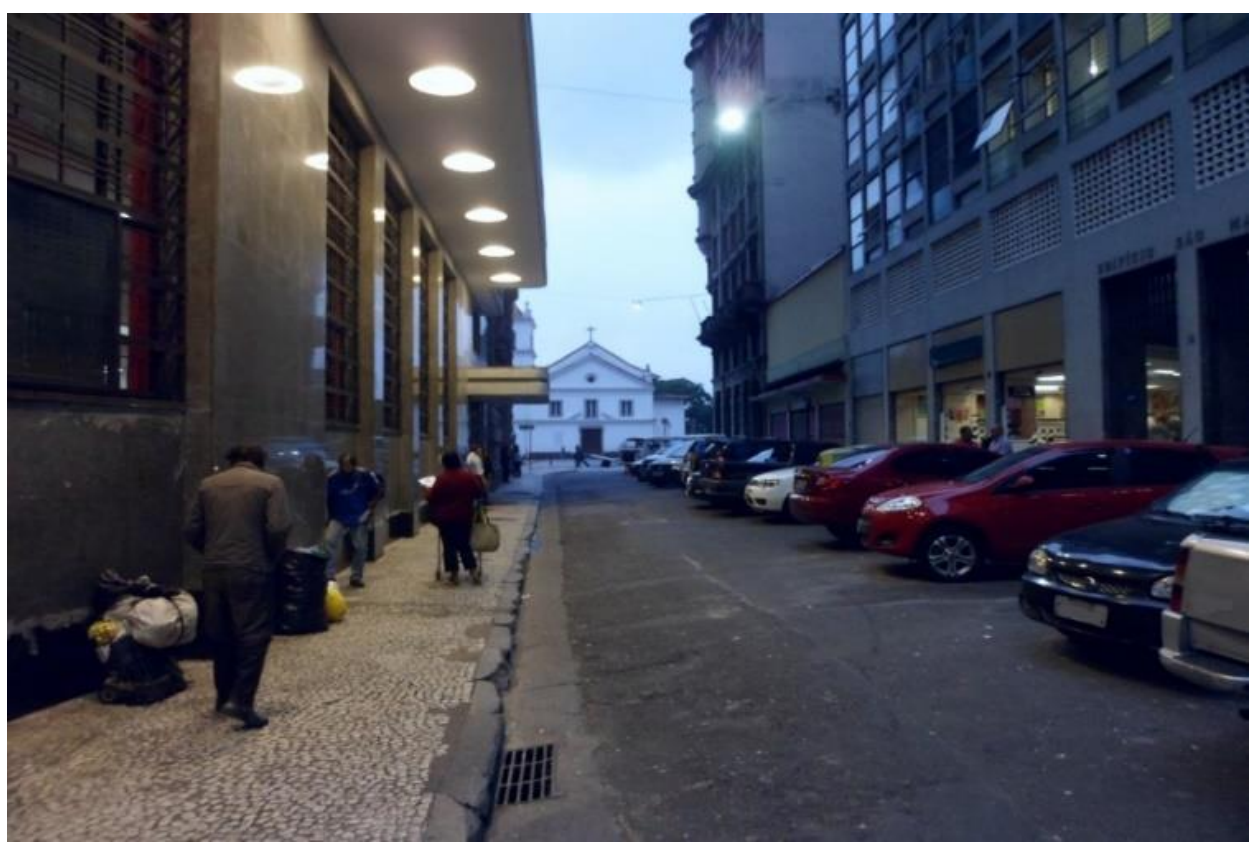

Figura 3: O "súbito encanto" ao ver, parcialmente, o Pateo. Foto: Ivan Fortunato, abr./2013.

Mas, por que tal imagem - seja observada como a cidade lá fora ou vivida dentro da paisagem - seria uma "traição" à mensagem urbana? Isso se deve, justamente, porque o encanto é algo pessoal, mesmo que outros também possam manifestar emoção igual ou semelhante. Por isso, como pesquisador, foi necessário dar voz ao lugar, permitindo sua manifestação coletiva. Daí a necessidade de compreendê-lo sob múltiplas perspectivas.

Ainda assim, por mais perspectivas que se envolvam, parece sensato afirmar que um lugar jamais será compreendido de forma pronta e acabada. Isso decorre da complexa relação tripartida lugar-cidade-sujeitos e da óbvia constatação que, frequentemente, cada elo dessa relação se transforma e pelo outro é transformado, impedindo que o que se comunica no entremeio seja cristalizado de forma perene, mas somente transitória. E não se pode estabelecer em quanto tempo tais mudanças ocorrem. Tomando o Pateo como exemplo, verifica-se que tudo pode permanecer estacionário por séculos, ou pode transmutar da noite para o dia.

Ao tomar as cidades como um complexo sistema comunicativo, Ferrara (2008) apresentou ideias parecidas, capazes de ampliar o sentido desta evidência três para ComunicaCidade, que se revela na interação comunicacional entre lugar-cidade-sujeito. Segundo a autora: 
[...] para apreender a cidade é necessário acompanhar sua circularidade comunicativa que nos leva a saber distinguir entre um sistema construído, o valor por ele emitido e a interação que permite que a cidade seja diferente de ambos [...] a cidade é, ao mesmo tempo, objeto comunicativo e sujeito da própria interação que nela se desenvolve (FERRARA, 2008, p. 43).

As considerações sobre a comunicação na e da cidade registradas cooperam com a seguinte síntese sobre a tríplice relação comunicativa aqui delineada: (1.) há uma dimensão ontológica no lugar, o que implica reconhecer seu envolvimento com a cultura, participando de suas modificações; (2.) a cidade se comunica por meio de seu patrimônio, seja como sujeito, como objeto, como ambos; (3.) o pesquisador se envolve com o lugar e com a cidade pela sua própria percepção e suas emoções, o que pode facilitar certa "traição" à comunicação da e com o lugar, pois sua interpretação pode ser estritamente particular.

\section{Ao final}

O trecho da Rua Hudson onde moro é todo dia cenário de um complexo balé de calçada. Eu mesma entro em cena pouco depois das oito, quando coloco do lado de fora a lata de lixo, sem dúvida uma tarefa prosaica, mas gosto do meu papel, do barulinho metálico que produzo, na hora em que passam as levas de colegiais pelo meio do palco, deixando cair papel de bala [...] Enquanto varro os papéis de bala, observo os outros rituais matinais (JACOBS, 2003, p. 53).

Para ensaiar a ComunicaCidade como um conceito capaz de ajudar a compreender melhor as relações estabelecidas com um cidade, três evidências foram elencadas como fundantes. Começamos por "ver e ouvir" a cidade, a qual implica estar na cidade, imerso em suas ruas e avenidas, prédios e parques, enfim, na cidade, vivendoa. Na sequência, tratamos do "patrimônio e sua ordem subjacente", demonstrando como o patrimônio construído é poderoso meio de comunicação, pois permite que se reconheça parte da cidade desde seu primeiro momento nela; os diferentes tipos de construção, os locais em que estão, sua altura etc., são poderos símbolos de comunicação, mesmo que silenciosos. Por fim, a última evidência diz respeito ao "patrimônio e a subjetividade", pois, tanto os lugares quanto as pessoas são seres ontológicos e sua comunicação, portanto, é algo orgânico, dinâmico, imprevisível até.

Na epígrafe desta última seção, é possível localizar as três evidencias elencadas para delinear a ComunicaCidade. Primeiro, as palavras "cenário" e "barulhinho" representam, respectivamente, o ver e o ouvir a cidade. Segundo, a Rua Hudson esconde uma ordem subjacente, tida como um "complexo balé", que começa quase sempre no mesmo horário e envolve várias tarefas prosaicas (as quais a autora investe as quatro páginas seguintes descrevendo, em detalhes) que compõe o mencionado ritual. Os elos do tripartido que se comunica são: Nova Iorque, a cidade; Rua Hudson, o lugar; a autora, 
o sujeito que, ciente da possível traição, coloca-se como autora do balé que acontece na cidade lá fora.

Ao final, o que se espera de todo esforço ComunicaCitadino realizado neste ensaio é que: (1.) os pressupostos esboçados não sejam compreendidos como uma parcela de uma teoria da comunicação pronta e acabada e, (2.) que mais pesquisadores se envolvam com a tríplice comunicativa cidade-lugar-sujeito, permitindo que essa conjectura sobre uma possível ComunicaCidade não ressoe no vazio das ciências, mas que reverbere aqui e ali, elevando o valor das cidades.

\section{Referências}

CALVINO, Í. As cidades invisíveis. São Paulo: Folha, 2003.

CALVINO, I. Marcovaldo ou as estações na cidade. São Paulo: Cia. das Letras, 1994.

CANEVACCI, M. A cidade polifônica: ensaio sobre a antropologia da comunicação urbana. 2a . ed. São Paulo: Nobel, 1997.

DARDEL, E. O homem e a Terra: natureza da realidade geográfica. São Paulo: Perspectiva, 2011.

FERRARA, L. Cidade: meio, mídia e mediação. MATRIZes, São Paulo, v. 1, n. 2, p. 39$53,2008$.

FERRARA, L. Os significados urbanos. São Paulo: EDUSP, 2000.

FORTUNATO, I. Ensaiando formas urbanas: geograficidades nos processos socioespaciais. Revista Geográfica Venezolana, Mérida, v. 59, n. 1, p.206-211, 2018.

FORTUNATO, I. O Largo Pateo do Collegio e o súbito encanto com o lugar. Caderno de Geografia, Belo Horizonte, v. 27, n. 48, p. 104-122, 2017.

FORTUNATO, I. Memórias do Pateo do Collegio como lugar pioneiro da educação paulistana. Cadernos do CEOM (Unochapecó), Chapecó, v. 29, n. 44, p. 37-42, 2016a.

FORTUNATO, I. Patrimônio e Memória: o Pateo do Collegio como testemunho da urbanização da cidade de São Paulo. Museologia e Patrimônio, Rio de Janeiro, v. 9, n. 2, p. $81-100,2016 b$.

FORTUNATO, I. Notes about place from a geographicity standpoint. Revista Geográfica Venezolana, Mérida, v. 57, n. 1, p. 126-133, $2016 \mathrm{c}$.

FORTUNATO, I. Historicidade e geograficidade do Pateo do Collegio, coração do centro histórico de São Paulo. Coletânea, Rio de Janeiro, v. 14, n. 27, p. 109-133, 2015

FORTUNATO, I. Pateo do Collegio: um lugar na cidade de São Paulo. Tese (Doutorado em Geografia). Rio Claro: IGCE/UNESP, 2014.

HILLMAN, J. Cidade \& Alma. São Paulo: Studio Nobel, 1993. 
JACOBS, J. Morte e vida de grandes cidades. São Paulo: Martins Fontes, 2003.

SOMEKH, N. A cidade vertical e o urbanismo modernizador: São Paulo 1920 - 1939.

São Paulo: Nobel, 1997.

UN. United Nations. World urbanization prospects: The 2014 Revision. Department of Economic and Social Affairs, Population Division, 2015.

WILHEIM, J. O substantivo e o adjetivo. São Paulo: Perspectiva, 1976.

\begin{abstract}
Ivan Fortunato
Doutor em Geografia e Doutor em Desenvolvimento Humano e Tecnologias, ambos pela UNESP de Rio Claro. Professor do IFSP, Itapetininga, e dos programas de pósgraduação em Ciências Humanas e Sociais, da UFABC, e em Educação, da UFSCar, Sorocaba.

Av. João Olimpio de Oliveira, 1561, Vila Asem, CEP: 18202-000, Itapetininga/SP

E-mail: ivanfrt@yahoo.com.br
\end{abstract}

Recebido para publicação em maio de 2018 Aprovado para publicação em agosto de 2018 